\title{
Factors Predicting the Good Level of Knowledge, Attitudes and Practices of Heads of Household and Nursing Staff on Canine Rabies in the City of Matadi, DRC
}

\author{
Marthe Ndenge Hello ${ }^{1}$, Prince Kimpanga ${ }^{2}$, Paulin Mutombo ${ }^{2}$, Phillipe Kone ${ }^{3}$, \\ Dani Yassa Ndjakani ${ }^{1}$, Vincent Bonkela ${ }^{3}$, Parfait Ndongo ${ }^{4}$, Blaise Makoso Nimi ${ }^{5,}$, *, Nkembi Nzuzi ${ }^{2}$ \\ ${ }^{1}$ Epidemiology Department Ministry of Public Health, Kinshasa, DR of Congo \\ ${ }^{2}$ School of Public Health, University of Kinshasa, Kinshasa, DR of Congo \\ ${ }^{3}$ United Nations Food Organization, Kinshasa, Democratic Republic of Congo \\ ${ }^{4}$ Department of Veterinary Medicine, National Pedagogical University, Kinshasa, Democratic Republic of Congo \\ ${ }^{5}$ Department of Internal Medicine, University of Kinshasa, Kinshasa, Democratic Republic of Congo \\ ${ }^{6}$ Department of Internal Medicine, University of President Joseph Kasa-Vubu, Boma, Democratic Republic of Congo
}

Email address:

docteurmakoso@gmail.com (B. M. Nimi)

${ }^{*}$ Corresponding author

\section{To cite this article:}

Marthe Ndenge Hello, Prince Kimpanga, Paulin Mutombo, Phillipe Kone, Dani Yassa Ndjakani, Vincent Bonkela, Parfait Ndongo, Blaise Makoso Nimi, Nkembi Nzuzi. Factors Predicting the Good Level of Knowledge, Attitudes and Practices of Heads of Household and Nursing Staff on Canine Rabies in the City of Matadi, DRC. Animal and Veterinary Sciences. Vol. 9, No. 4, 2021, pp. 115-120.

doi: $10.11648 /$ j.avs.20210904.15

Received: June 26, 2021; Accepted: July 15, 2021; Published: August 19, 2021

\begin{abstract}
Rabies is a viral zoonosis caused by several viruses of the Genus Lyss virus, including all mammals are sensitive. The disease is responsible for 55,000 deaths with a lethality of $100 \%$, per year worldwide; between 2011 and 2012 , it caused death in Asia (31,000 deaths), and (24,000 deaths) in Africa. An endemic zoonosis in the DRC especially in the province of central Congo (Matadi), causing 131 deaths including 14 between 2009 and 2011 An analytical (quantitative) study was conducted in the city of Matadi in Kongo Central in order to determine the predictive factors of level of knowledge, attitudes and practices of rabies, on a sample of 422 participants interviewed. The results show that the factors linked to the correct CAP level for rabies were as follows: male sex $(\mathrm{OR}=3.068 ; \mathrm{p}=0.000)$; good knowledge of the clinical signs of rabies $(\mathrm{OR}=$ $6.467 ; \mathrm{p}=0.000)$; dog breeding $(\mathrm{OR}=2.138 ; \mathrm{p}=0.001)$; and a good knowledge of means of prevention of rabies $(\mathrm{OR}=6.217$; $\mathrm{p}=0.000)$; It is important to encourage the breeding of dogs in a tethered lifestyle, promote awareness and a health education program aimed at spreading the principles of rabies prevention and control in order to correct some common misconceptions in the population.
\end{abstract}

Keywords: Factors, CAP, Rage, Kongo Central, Democratic Republic of Congo

\section{Introduction}

Rabies is a viral zoonosis caused by several viruses of the Lyssavirus genus and to which all mammals are susceptible. Humans can be accidentally infected as a result of a bite or scratch from a shedding animal and this almost always results in rapid death after the onset of the clinical phase. While canine rabies is eradicated in other continents of the world, it is still present and is responsible for 55,000 deaths per year worldwide, with 31,000 deaths in Asia and 24,000 in Africa [1].

These deaths are more common in rural areas for lack of accessibility to adequate post-exposure prophylaxis (PEP), the causes of which are, the high cost of care (PEC), the prolificacy of dogs, the difficulty of accessing resources, the lack of knowledge of the population on the practices to be carried out before and after exposure [2].

Rabies is a neglected disease affecting poor and vulnerable 
populations in which deaths are rarely reported and human vaccines and immunoglobulin are not readily available or accessible.

It occurs mainly in remote rural communities where children between the ages of 5 and 14 are frequent victims [WHO, Rabies. Fact sheet N 99, March 2016].

The average cost of post exposure prophylaxis (PEP) can be catastrophic expenses for underprivileged populations, since treatment can cost US \$40 (US \$) in Africa and US \$49 in Asia, where the average daily income is 1 to 2 USD per person [3].

In the vast majority of cases, rabies is transmitted to humans by the bite of an infected dog and to a lesser extent, by licking. The dog constitutes the reservoir and the main vector of the rabies virus in the two continents mentioned above. It is responsible for $95 \%$ of human rabies cases in Asia and Africa [4].

The disease has no curative treatment once it is declared, but it can be prevented by vaccination before exposure in animals and after exposure in humans [5]. Only prevention can curb the fatal outcome of this contagious disease, which occupies the first rung of the lethality scale.

Preventive vaccination of companion animals exists but the vaccine is currently imported when it was once produced locally by the Veterinary Laboratory of Kinshasa. This vaccine is effective and breaks the chain of transmission of the disease flawlessly as soon as approximately $70 \%$ of the animals in a region or country are vaccinated [6-10].

In 2009, the Kinshasa Central Veterinary Laboratory received and tested 20 canine samples from the lower Congo, of which 12 were positive for rabies [7, 10-13].

Our study was carried out in the city of Matadi, Kongo Central Province in the Democratic Republic of Congo and aimed to determine the predictive factors of the good level of CAP of heads of household and nursing staff in the city of Matadi on rabies, to describe the socio-demographic characteristics of the heads of household as well as of the nursing staff in the town of Matadi; assess the level of Knowledge, Attitudes and Practices of respondents.

\subsection{Method}

We conducted a cross-sectional and descriptive study at Matadi city in the south-east and $366 \mathrm{~km}$ from Kinshasa, the capital of DR Congo. This province with an agropastoral vocation has an area of $53,920 \mathrm{~km}^{2}$ whose Latitude is - 5.0381171 and Longitude is 18.8258946. It was conducted using a semi-structured questionnaire and tested in the municipality of Mont ngafula city province of Kinshasa in order to collect on the determinants of the good CAP level of heads of households and nursing staff on rabies in Matadi city. The sampling technique used was a probability method used in households with multistage sampling proportional to the sample size $(n=422)$ according to the following technique: i) first stage; we had randomly drawn 5 districts per municipality in a random manner; ii) in the second stage, we had randomly selected 2 avenues in each district retained in the drawn clusters; iii) in the third stage, households were drawn randomly from the streets of each neighborhood. In health facilities, it was a reasoned choice based on the number of providers present on the day of the survey.

\subsection{Data Analysis}

The information collected was entered using EPI data version 2 software and analyzed using Statistical Package for the Social Sciences (SPSS) version 20 software. The results were presented by frequencies for the quantitative and qualitative variables grouped in tabular form. Associations were found using the Chi-Square test, and the obvious variables were put into a logistic regression model to identify predictors of rabies in the town of Matadi. For each variable retained, we calculated the Odds Ratio (OR: 95\%) to identify any associations between the dependent variable and the independent variables.

To do this, certain variables were dichotomized as follows: i) the level of education at high (higher, secondary) and low (primary, uneducated) levels;) religion in Christian religions (revival churches, Protestant and Catholic churches) and nonChristian religions (Islam and others); iii) household size in large family ( $\geq 7$ people) and small family ( $\pm 1-6$ people); iv) Knowledge: in a good knowledge of the signs of rabies for having cited at least 3 signs and poor knowledge for having cited less than three signs; v) perception of the severity of rabies: good perception of the severity of complications (very serious and serious), poor perception (not very serious, not at all serious and don't know); vi) practice: good practice (keep dogs tied, need to vaccinate humans and dogs, call veterinary services); bad practice (raising the dog to stray, not needing to vaccinate humans and dogs, not using veterinary services); vi) the CAP level: at a good CAP level (have a good knowledge, a good perception and a good practice on rabies); poor CAP level (having poor knowledge, poor practice and poor perception of rabies). In the present study, the correct CAP level for rabies was the dependent variable; measured at the nominal binary scale.

\subsection{Ethical Considerations}

During the study, the selected persons were followed in a confidential manner respecting the ethical considerations according to the Declaration of Helsinki II and an informed consent form was signed by all the respondents.

All participants provided written informed consent.

\section{Results}

Of the 422 participants, $124(29.4 \%)$ were Females while $298(70.6 \%)$ were males. Most of the respondents represented a high level of education, i.e. (92.9\%), and the household size of $>6$ people was more represented, i.e. $84.9 \%$ of respondents; and Christians were more representative (76.1\%). High level of education was higher among those surveyed at 92.9\%. (Table 1). 
Table 1. General characteristics of the study population.

\begin{tabular}{|c|c|c|c|}
\hline Factors & Modalities & Over All & $\%$ \\
\hline \multirow{2}{*}{ Sex } & Men & 298 & 70,6 \\
\hline & Women & 124 & 29,4 \\
\hline \multirow{2}{*}{ Instruction level } & Low & 30 & 7,1 \\
\hline & high & 392 & 92,9 \\
\hline \multirow{2}{*}{ Religion } & Christian & 321 & 76,1 \\
\hline & No Christian & 101 & 23,9 \\
\hline \multirow{2}{*}{ Household size } & Small family ( $\leq 6$ personnes) & 64 & 15,1 \\
\hline & Big family (> 6 personnes) & 358 & 84,9 \\
\hline \multirow{2}{*}{ Middle } & Urban & 421 & 99,7 \\
\hline & Rural & 1 & 0,3 \\
\hline
\end{tabular}

It turns out from this study that $88.6 \%$ of household heads had a good knowledge of the mode of transmission of rabies and among them, only $68.7 \%$ had a good knowledge of the clinical signs of rabies, $74.7 \%$ had a good knowledge of the means of prevention of rabies and $83.3 \%$ had a good knowledge of the veterinary services. On the health personnel side, $76.2 \%$ of health providers had a good knowledge of the definition of rabies cases and $61.9 \%$ had a good knowledge of the incubation period (Table 2).

Emerges from this table that $58.8 \%$ of the respondents raised dogs; $60 \%$ let their dogs wander, $54.5 \%$ had a good perception of the severity of rabies, while $75.6 \%$ showed a good perception of the means of controlling rabies. It emerges from this study that $58.8 \%$ of heads of households raised dogs, among them $60 \%$ let their dogs wander against $40 \%$ who tied the dogs. Almost $54.5 \%$ had a good perception of the severity of rabies, $75.6 \%$ a good perception of the means of controlling rabies, $100 \%$ of providers had a good knowledge of the means of vaccine storage, and 95, 2\% mastered the means of combating rabies (Table 3 ).

In this study, $16(76.2 \%)$ of providers had good knowledge of the rabies case definition and $13(61.9 \%)$ had good knowledge of rabies incubation duration. All providers had a good knowledge of the means of rabies control and 20 (95.2\%) had a good knowledge of the means of controlling rabies. (Table 4).

Table 2. Distribution of the population according to knowledge about rabies.

\begin{tabular}{|c|c|c|c|}
\hline Factors & Modalities & Over All & $\%$ \\
\hline \multirow{2}{*}{ Transmission mode } & Good & 374 & 88,6 \\
\hline & Bad & 48 & 11,4 \\
\hline Clinical signs & Good & 290 & 68,7 \\
\hline \multirow{2}{*}{ Means of prevention } & Good & 315 & 74,7 \\
\hline & $\mathrm{Bad}$ & 107 & 25,3 \\
\hline Veterinary services & Good & 351 & 83,2 \\
\hline
\end{tabular}

Table 3. Attitudes and practices of heads of households on rabies.

\begin{tabular}{|c|c|c|c|}
\hline Factors & Modalities & Over All & $\%$ \\
\hline \multirow{2}{*}{ Dog breeding } & Yes & 248 & 58,8 \\
\hline & No & 174 & 41,2 \\
\hline \multirow{2}{*}{ Dog lifestyle } & Straying & 149 & 60 \\
\hline & Attached & 99 & 40 \\
\hline \multirow{2}{*}{ Need to be vaccinated } & Yes & 247 & 58,5 \\
\hline & No & 175 & 41,5 \\
\hline Perception of gravity & Good & 230 & 54,5 \\
\hline \multirow{2}{*}{ Perception of medium struggle } & Good & 319 & 75,6 \\
\hline & $\mathrm{Bad}$ & 103 & 24,4 \\
\hline
\end{tabular}

Table 4. Knowledge, Attitude and Practice of nursing staff on rabies.

\begin{tabular}{|c|c|c|c|}
\hline Factors & Modalities & Over All & $\%$ \\
\hline \multirow{2}{*}{ Knowledge of case definition } & Good & 16 & $76,2 \%$ \\
\hline & $\mathrm{Bad}$ & 5 & $23,8 \%$ \\
\hline \multirow{2}{*}{ Knowledge of incubation times } & Good & 13 & $61,9 \%$ \\
\hline & Bad & 8 & $38,1 \%$ \\
\hline \multirow{2}{*}{ Vaccine conservation knowledge } & Good & 100 & 100 \\
\hline & Bad & 0 & $0,0 \%$ \\
\hline Average wrestling knowledge & GoodBad & 201 & $95,2 \% 4,8 \%$ \\
\hline
\end{tabular}


In univariate analysis 8 factors emerged as explanations of a good CAP level on rabies among which - The chance of having a good CAP level for rabies was 3 times higher among male respondents than female respondents $(\mathrm{OR}=$ 3.068; $p=0.000)$; - The chance of having a good CAP level for rabies was 4 times higher among respondents with a good knowledge of the mode of transmission of rabies $(\mathrm{OR}=$ $4.018 ; \mathrm{p}=0.000) ;-$ The chance of having a good CAP level for rabies was 6 times higher among respondents with a good knowledge of the clinical signs of rabies $(\mathrm{OR}=6.467 ; \mathrm{p}=$ 0.000); - The chance of having a good CAP level on rabies was 6 times higher among respondents who had a good knowledge of means of preventing rabies $(\mathrm{OR}=6.217$; $\mathrm{p}=$ $0.000)$; - The chance of having a good CAP level for rabies was twice as high among respondents who raised dogs $(\mathrm{OR}=$ 2.138; $\mathrm{p}=0.001)$; - The chance of having a good CAP level on rabies was twice as high among respondents who tethered their dogs $(\mathrm{OR}=2.436 ; \mathrm{p}=0.000) ;-$ The chance of having a good CAP level for rabies was twice as high among respondents who had a good perception of the severity of rabies $(\mathrm{OR}=1.947 ; \mathrm{p}=0.000)$; - The chance of having a good CAP level for rabies was 3 times higher among respondents who had a good perception of means of controlling rabies $(\mathrm{OR}=3.151 ; \mathrm{p}=0.003)$ (Table 5).

Logistic regression reveals four (4) factors associated with persistence of rabies The chance of having a good CAP level for rabies was 3 times higher among male respondents than female respondents $(\mathrm{OR}=3.068 ; \mathrm{p}=0.000)$; The chance of having a good CAP level for rabies was 6 times higher among respondents who had a good knowledge of the clinical signs of rabies $(\mathrm{OR}=6.467 ; \mathrm{p}=0.000)$; The chance of having a good CAP level for rabies was twice as high among respondents who raised dogs $(\mathrm{OR}=2.138 ; \mathrm{p}=0.001)$;

The chance of having a good CAP level on rabies was 6 times higher among respondents who had a good knowledge of means of rabies prevention $(\mathrm{OR}=6.217 ; \mathrm{p}=0.000)$ (Table 6$)$.

Table 5. Association between the explanatory factors and the correct CAP level for rabies.

\begin{tabular}{|c|c|c|c|c|c|}
\hline Factors & Modalities & Good levelCAP & OR & IC à $95 \%$ & $\mathbf{p}$ \\
\hline \multirow{2}{*}{ Sex } & Male & $298(70,6 \%)$ & 3,262 & {$[2,064-5,154]$} & $0,00 *$ \\
\hline & Female & $124(29,4 \%)$ & 1 & - & - \\
\hline \multirow{2}{*}{ Transmission Mode } & Good & $374(86,6 \%)$ & 4,018 & {$[2,168-7,488]$} & $0,000 *$ \\
\hline & Bad & $48(11,4 \%)$ & 1 & - & - \\
\hline \multirow{2}{*}{ Clinical signs } & Good & $290(68,7 \%)$ & 6,467 & {$[4,030-10,377]$} & $0,000 *$ \\
\hline & $\mathrm{Bad}$ & $132(31,3 \%)$ & 1 & - & - \\
\hline Means of prevention & Good & $315(74,7 \%)$ & 6,217 & {$[3,834-10,80]$} & $0,00 *$ \\
\hline \multirow{2}{*}{ Dog breeding } & Yes & $248(58,8 \%)$ & 2,138 & {$[1,337-3,318]$} & $0,001 *$ \\
\hline & No & $174(41,2 \%)$ & 1 & - & - \\
\hline \multirow{2}{*}{ Perception of gravity } & Good & $230(54,5 \%)$ & 1,947 & {$[1,255-3,020]$} & $0,003 *$ \\
\hline & Bad & $192(45,5 \%)$ & 1 & - & - \\
\hline \multirow{2}{*}{ Dog lifestyle } & Attached & $149(60 \%)$ & 2,436 & {$[1,469-4,036]$} & $0,004 *$ \\
\hline & Divagation & $99(40 \%)$ & 1 & - & - \\
\hline Perception of means of struggle & Good & $319(75,6 \%)$ & 3,154 & {$[1962-5,0687]$} & $0,003 *$ \\
\hline
\end{tabular}

Table 6. Actors predicting a good CAP level for rabies.

\begin{tabular}{|c|c|c|c|c|c|c|c|}
\hline \multirow{3}{*}{ Factor } & \multicolumn{7}{|c|}{ Good CAP level } \\
\hline & \multicolumn{4}{|c|}{ Bi-varied analysis } & \multicolumn{3}{|c|}{ Logistic regression } \\
\hline & Modalitie & OR & IC à $95 \%$ & p & Adjusted OR & IC à $95 \%$ & $\mathbf{P}$ \\
\hline \multirow{2}{*}{$\begin{array}{l}\text { Knowledge of signs of } \\
\text { rabies }\end{array}$} & Good & 6,467 & {$[4,030-10,377]$} & $0,000^{*}$ & 3,698 & {$[2,161-6,114]$} & $0,000 *$ \\
\hline & Bad & 1 & - & - & - & - & - \\
\hline \multirow{2}{*}{ Dog draining } & Yes & 2,138 & {$[1,337-3,318]$} & $0,001 *$ & 5,525 & {$[2,130-14,33]$} & $0,023 *$ \\
\hline & No & 1 & - & - & - & - & - \\
\hline $\begin{array}{l}\text { Average knowledge of } \\
\text { prevention }\end{array}$ & Good & 6,217 & {$[3,834-10,80]$} & $0,000 *$ & 3,764 & {$[2,209-6,414]$} & $0,000 *$ \\
\hline \multirow{2}{*}{ Sex } & Male & 3,262 & {$[2,064-5,154]$} & $0,00 *$ & 2,492 & {$[1,474-4,213]$} & $0,001 *$ \\
\hline & women & 1 & - & - & - & - & - \\
\hline
\end{tabular}

\section{Discussion}

In this study, we determined the predictive factors of the good level of knowledge, attitudes and practice of heads of households and nursing staff on canine rabies in the city of Matadi in the province of Kongo central in the Democratic Republic of Congo.

The socio-demographic characteristics of household heads showed in the survey that the male sex was more represented (70.65) than the female sex (29.4\%) [14]. This strong representativeness is explained by the fact that the majority of household heads were men and these results are close to those found by Widyastuti in Indonesia where men were more represented (82\%) [15].

In general, the people surveyed represented a high level of education, ie $(92.9 \%)$. Our results differ from those found by Ichhpujani $\mathrm{R}$ et al [16] in India where $75.1 \%$ of respondents 
were illiterate, this discrepancy could be explained by the fact that we had conducted this study in an urban environment.

The mode of transmission of rabies was known to $88.6 \%$ of heads of household and these results differ from those found by $\mathrm{R}$. Pa Yaoundé where $100 \%$ of heads of households had a good knowledge of the means of transmission of rabies [17]. This difference can be explained by the fact that there is not a good awareness against rabies in the DRC. The study showed that $74.7 \%$ of the respondents had a good knowledge of the means of rabies prevention and these results differ from those found by Matibag GC et all in Asia where $88 \%$ of the heads of households had a good knowledge of the means. rabies prevention [14].. This difference can be explained by a low awareness of the means of preventing rabies [14]. The veterinary services were known to $83.3 \%$ of the respondents and our results contradict those found by Rakotonirainy $\mathrm{N}$ et al in Madagascar where only $7 \%$ of the heads of households had a good knowledge of the veterinary services. This difference can be explained by the fact that our study was conducted in an urban setting [18].

The promotion of the elements identified above can allow respondents to have the right CAP level. Regarding the factors related to the correct CAP level on rabies, - The male sex $(O R=3.068 ; p=0.000)$ had a strong representativeness explained by the fact that the majority of household heads were men. These results are close to those found by Widyastuti $\mathrm{M}$ et al [15]. in Indonesia where men were more represented, ie $82 \%$. Good knowledge of the clinical signs of rabies $(O R=6.467 ; p=0.000)$ : this situation is due to the fact that the majority of respondents had a high level of education. These results corroborate those found by Mucheru G et al Kenya in 2014 [17-19]., where participants who had sufficient knowledge of the signs of rabies were more likely to seek appropriate care $(\mathrm{OR}=3.0)$.

Dog breeding $(\mathrm{OR}=2.138 ; \mathrm{p}=0.001)$ : This situation is explained by the fact that respondents raised dogs for hunting and companionship (guarding). These results are in the same direction as those found by Matibag et al in 2007 in Sri Lanka [14]. - A good knowledge of means of preventing rabies $(\mathrm{OR}=6.217 ; \mathrm{p}=0.000)$ : this could be explained by a high level of education of the respondents. These results differ from those found in Côte d'Ivoire by D. Ngaroua et al in 2015 which showed gaps in knowledge, attitudes and practice in the prevention of rabies in this population. This requires a strengthening of the health education program aimed at disseminating the principles of rabies prevention and control [20-22].

\section{Conclusion}

The present study made it possible to determine the predictive factors of the good level of knowledge, attitudes and practices on rabies, in particular, a good knowledge of the signs of rabies, lifestyle of tethered dogs, the male sex and a good knowledge of the means of prevention. However, unhealthy practices persist. It is therefore necessary to increase the awareness of the population concerning this serious disease.

\section{Conflict of Interest}

The authors declare no conflict of interest.

\section{Acknowledgements}

The Center for the Prevention and Control of Diseases (CDC) for the financial support of this study To the Food and Agriculture Organization of the United Nations (FAO) for technical support The Provincial Fisheries and Livestock Division of Kongo Central for support and supervision The Provincial Division of Public Health of Kongo Central for agreeing to be part of the study STATE.

\section{References}

[1] WHO., Rabies. Fact sheet $n^{\circ}$ 99, 2012.

[2] Corine Jamma., La rage. Institut Pasteur press service: -01 40 61 3. WHO., Rabies. Fact sheet $N^{\circ}$ 99, March 2016.

[3] OIE Bulletin, 2014.

[4] WHO., Expert consultation on rabies Technical report series 931. First report. Geneva, 2005.

[5] Shwiffs. Hampson K., Anderson A., Potential economic benefits of eliminating canine rabies. Antiviral Res., 98, 352356, 2013.

[6] http: www.oie.int-fr-normes-mcode-fr., Cap of canine rabies. OIE, 2011.

[7] Ministry of Public Health., Guide for the management of epidemics in a health zone, 2015.

[8] Katinka de Balogh, Canine rabies, 2009.

[9] Ghosh TK., Controrsiens in rabies vaccination. Indian J Pediatric, 2003.

[10] The importance of pet rabies vaccination, published on Thu, 30/01/2014 - 1343 / Modified on Sat 08/08/2015 - 10: 42

[11] Ministry of Public Health., Technical guide for integrated disease surveillance and response, IDSR, 2nd Edition, RD. Congo, 2011.

[12] www.oie.int.fr., Animal-Health-in-the-World. OIE Fact Sheet, 2015.

[13] Matibag G et al, 2007, Knowledge, attitudes, and practices survey of rabies in a community in Sri Lanka.

[14] Widyastuti $\mathrm{M}$ et al, 2015, On dogs, people, and a rabies epidemic. Results from a sociocultural study in Bali, Indonesia, Infect Dis Poverty, 2015.

[15] Ichhpujani RL., Chhabra M., Mittal V., Bhattacharya D., Singh J, Lal S., Knowledge, attitude and practices about animal bites and rabies in general community - a multi-centric study, 2006. 
[16] Mucheru G et al, 2014, Knowledge and practices towards rabies and determinants of dog rabies vaccination in households. A cross sectional study in an area with high dog bite incidents in Kakamega County, Kenya, Pan Afr Med J, 2013-2014.

[17] Fatima., IRGUI., Perception of rabies by the Moroccan population, 2013

[18] IssakaTiembré et al, 2008, Knowledge, attitudes and practices of household heads in the commune of Abobo (Abidjan, Côte d'Ivoire) regarding rabies, Raccourcis Santé Publique 2014/4 (Vol. 26) Pages: 160.

[19] D Ngaroua, Djibrilla Yaouba, Salissou Bouba, Sandrine Kwedi, Marcel Tamanji, OumarouBello, Community perception of prevention against human rabies in a Health
District of Ngaoundéré (Cameroon), Home > Vol 16, No $4>$ Ngaroua, 2015.

[20] R. P., Biyem-Assi district health survey in the OGDS - Oct. 2013 to March 2014.

[21] R. Mindekem, u. Kayali, n. Yemadji, a. g. ndoutamia, j. Zinsstag, 2005, Canine demography and its importance for the transmission of human rabies in n'djaména, Med Trop; 65: 5358 23. K. adjé, A. N'Dour, F. Coulibaly, A. Halidou, R. Mabeki, P. Koné; 2015; knowledge, attitudes and practices on post-exposure prophylaxis measures at Cheik AntaDiop University in Dakar.

[22] Ana Valente, FORTUNATO DEISE, 2012, perception of rabies by the population in Luanda (Angola). 